\title{
Mapping Norway - a Method to Register and Survey the Status of Accessibility
}

\author{
Sven Michaelis, ${ }^{a}$ Kathrin Bögelsack ${ }^{b}$ \\ ${ }^{a}$ Kartverket, Grandfjara 22b,6415 Molde,sven.michaelis@kartverket.no \\ ${ }^{b}$ Kartverket, Grandfjera 22b,6415 Molde, kathrin.bogelsack@kartverket.no
}

\begin{abstract}
The Norwegian mapping authority has developed a standard method for mapping accessibility mostly for people with limited or no walking abilities in urban and recreational areas. We choose an object-orientated approach where points, lines and polygons represents objects in the environment. All data are stored in a geospatial database, so they can be presented as web map and analyzed using GIS software. By the end of 2016 more than 160 municipalities are mapped using that method. The aim of this project is to establish a national standard for mapping and to provide a geodatabase that shows the status of accessibility throughout Norway. The data provide a useful tool for national statistics, local planning authorities and private users. First results show that accessibility is low and Norway still faces many challenges to meet the government's goals for Universal Design.
\end{abstract}

Keywords: Accessibility, methods, mapping, survey, Norway, public areas, urban areas, recreational areas, planning, wheel-chair, electrical wheelchair

\section{Introduction}

In 2009, the Norwegian Government issued "Norway universally designed by 2025", an action plan for universal design and increased accessibility [1]. The plan shows how the government will lay the foundation for achieving this goal through different time stipulated targets and measures.

The Norwegian Mapping Authority's (Kartverket) was commissioned to collect and standardize data about the current situation in municipal centers and recreational areas and make these data accessible for statistics, areal planning and private users.

\section{Method}

We have set up a project design based on a Finnish study [2]. The requirements were that all objects are saved together with their object features and their geographical information and the validation of accessibility should be based on measurable values.

It was necessary to find object types that represent the accessibility of an urban area. The number had to be high enough to get a relevant picture of the situation but not too high to handle the data amount from a national project. The choice fell on the following elements in urban areas: entrances to public buildings, HC-parking spots, car parks and the system of walkways within the municipal center. In recreational areas, we selected a variety of common objects like the path systems, picnic spots, fishing spots, toilets etc.

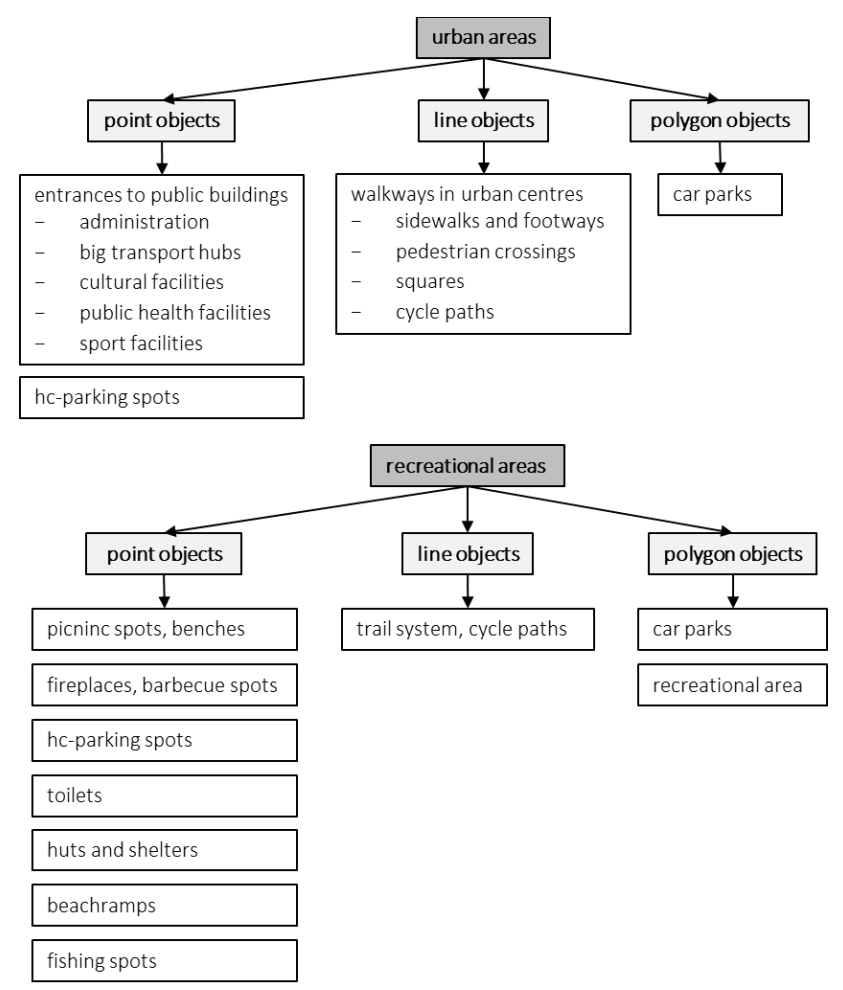

Fig. 1. Overview over objects mapped in urban areas and recreational areas.

We believe the information on accessibility of the selected objects provides a representative image of the accessibility of an area.

As main target group we choose people with limited or no walking abilities. This are the two group for which technical standards exist, that contain precise measurable values. We register also characteristics for blind and the partially sighted, but this is not yet our main focus. The 
existing technical standards are difficult to use in practical survey, especially by voluntary field workers.

As a next step, we had to develop guidelines for mapping of objects including a classification for the assessment of accessibility following the Norwegian Standard [3] and the Guidance document for structural engineering [4]. Concerning people with impaired mobility these standards focus on manual wheelchairs as the group with the highest requirements and therefore the key group for Universal Design, i.e. areas accessible to manual wheelchair users are accessible for all people with limited or no walking abilities. We added the category electrical wheelchair, based on a wheelchair type for combined inand outdoor use [5], currently the most common wheelchair type in Norway. Severally handicap organizations were integrated during the method developing.

Based on these technical standards we developed a classification scheme for the validation of accessibility for each object. The Classification scheme combines several object features into an overall assessment value for that single object, (e.g. features as inclination of ramp, door width, height of beam, height of door opener etc. define the accessibility the entrance to a building). Each object is assigned to one of the following categories: accessible, partially accessible, not accessible or not assessed.

In 2009 The Norwegian Mapping Authority started the data collection in South-Norway, then still using GPS, camera and paper-pad. The collected data were put manually into an excel sheet. Soon it showed that this method was unpractical and too time-consuming.

In order to make mapping more efficient an APP was developed. It can be installed on each Android tablet or mobile phone and is freely available for administrative users. The APP allows digitizing the objects on a map back-ground, adding an object picture, editing object features and giving an evaluation of accessibility.

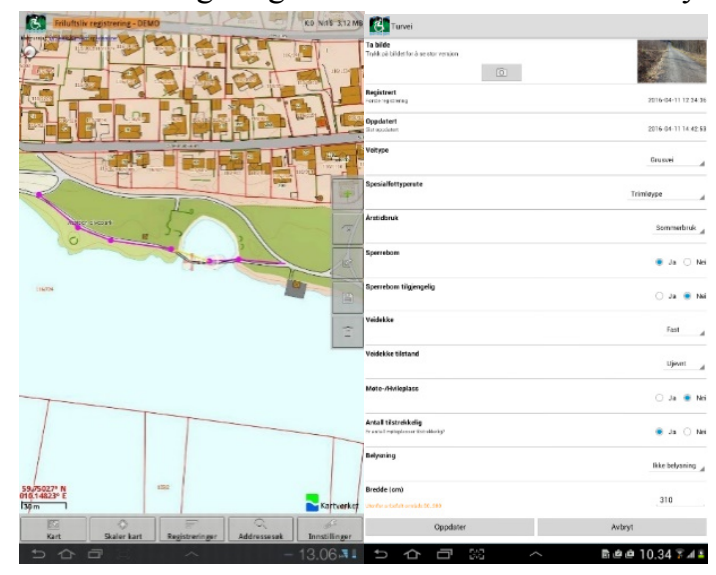

Fig. 2. The user surface of the APP during digitizing and editing of objects (left) and during mapping of object features (right).

During the pilot phase of the project the Norwegian Mapping authority carried out the initial data collection using mainly freelancers to map chosen communities throughout the country. The freelancers, mostly students, under-went extensive training and were supervised during the whole survey period. Since 2014, the project is in the process of going over into the operation phase where the responsibility for mapping is handed over to the municipalities.

The field device export the data immediately via cellphone network or Wi-Fi to a central server into a PostGIS database. 15 minutes after registration, all data will be published and one day after distributed via various sources.

We have used UML (Unified Modelling Language) to construct and visualize our data model (software Enterprise Architect). With the help of the UML model, its extension (GISTools for UML) and FME-based distribution software, the data can be harmonized and exported to various formats, like GML and SOSI (national data format in Norway). It is possible to download the data, to get a Web Map Service or Web Feature Service from Norway's national map data portal GEONORGE (www.geonorge.no ). A simple analyze tool is incorporated in GEONORGE and can be used to filter objects after their location and main features. That tool will enable users to, for example, find out how many HC-parking spots in a municipality are not accessible because they do not fit the size requirements. Additionally one can get access to our data via our information page http://www.kartverket.no/en/geodataarbeid/Accessibilityand-universal-design/ and our open map-client Norgeskart http://norgeskart.no/tilgjengelighet/.

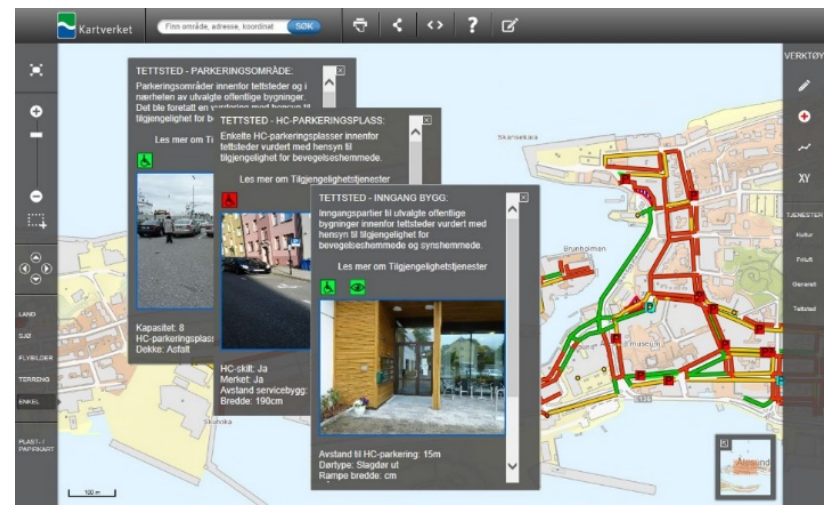

Fig. 3. The data are distributed over our map-client Norgeskart and are there accessible for the public. (red = not accessible, yellow $=$ partially accessible, green $=$ accessible $)$. By clicking on an object the object features show.

All mapped objects are then exported with their spatial information and measured values. This opens for:

- Publishing of data by standardized web services (public web maps, apps, etc).

- Spatial analysis is possible, for example availability of accessible $\mathrm{HC}$ parking spots in a distance of $25 \mathrm{~m}$ around the entrances to public health buildings.

- Feature analysis can determine why certain objects or a group of objects is not accessible.

Additionally storing objects with all their values and geographical information instead of just interpreted or de- 
rived information on accessibility of an object has the following advantages:

- Evaluation of accessibility can be adjusted to possible future changes in standards/technology.

- The validation of accessibility can be calculated automatically from the measured values.

- The database can be expanded, for instance with more categories of wheelchairs (wheelchairs for outdoor use etc.).

The focus on measurable values makes the mapping process easy and standardized and therefore increases the objectivity of the data. That makes it possible to, not only analyze and compare data within a municipality, but al-so to sum up bigger units like federal or national or compare different municipalities, towns etc..

\section{Results}

By the end of 2016 mapping is carried out in urban areas in 166 municipalities and recreational areas in 183 municipalities.

Analysis of the data shows that the overall accessibility in Norwegian municipalities is rather low. Only $1 \%$ of all HC-parking spots, $29 \%$ of all car parks, $6 \%$ of all entrances to public buildings and only $27 \%$ of all walkways are accessible for manual wheelchairs.

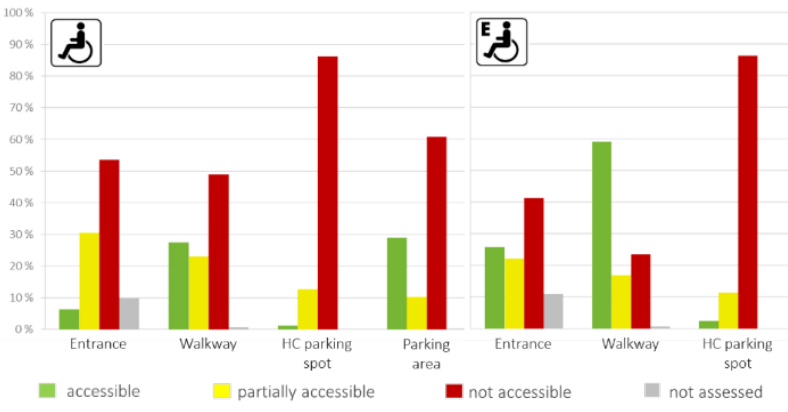

Fig. 4 Results for urban areas in Norway (status 2016) for manual wheelchairs and electrical wheelchairs. The main difference is that electrical wheelchairs handle a higher gradient and cross-fall.

The comparison of the results for electrical wheelchair and manual wheelchairs shows a clear difference between both groups for walkways and entrances (Figure 4). That indicates that gradient and cross-fall of walkways are major problems. Since all objects are mapped with their features, i.e. length and width for HC-parking spots gradient and railing for ramps etc. it is possible to precisely evaluate why objects are not accessible. Only $3 \%$ of $\mathrm{HC}$ parking spots meet the requirements for size and only $30 \%$ of car parks have enough designated HCparking spots. Entrances are not accessible because they do not have a HC-parking spot within $25 \mathrm{~m}$, have inaccessible ramps and either manual doors or no accessible door opener. Only few walkways in Norway have tactile or visual guidelines and only a fraction of these have guidelines that are in good condition. The biggest problem with walkways for wheel-chair users is the cross-fall, gradient and width.

Naturally, in recreational areas, the problems are even bigger, as here the surface is often uneven, tracks get washed out after heavy rains and due to Norway's topography the gradient is very rarely below the required value. Only $25 \%$ of all mapped tracks are accessible for electrical wheelchairs and that are often just short sections and not coherent walkways or even round-trips. Other objects like fishing spots, toilets, huts and $\mathrm{HC}$ parking spots are mostly not accessible. Here ramps are either lacking, are to steep and lack railing. The threshold of toilets and huts are too high and doors and the inside space is generally too small for wheelchairs. Car parks often have no HC-parking spots at all. However, when present $\mathrm{HC}$ parking spots are more accessible in recreational area than in urban areas.

\section{Conclusions}

\subsection{Methods}

Even though the method was developed to make the validation as objective and standardized as possible, several factors limit data comparability. The choice of mapped municipalities depended on the municipals interest to take part. The borders of the urban centers were established using data from Statistics Norway (http://www.ssb.no/en/ ) but the municipalities had the chance to adapt the borders. The choice of recreational are-as was entirely up to the municipalities. In the initial mapping we focused on public buildings and recreational areas in or in the close vicinity of urban centers. However, some municipalities used the method also to map private businesses and more recreational areas. That leads to an overrepresentation of interested municipalities in the data.

As the register APP is freely available for administrative users, we have to trust that the method is followed and that all participants feel an obligation towards the data quality and mapping standards requirements of the project. We are also aware of the fact that people perceive and handle technical tools in a very different way. When asking the field workers for their experience we got very different feedback, ranging from rather complicated and difficult to self-explanatory, logical and intuitive. To minimize subjective validation and mapping mistakes we tried to make the method and the register APP as intuitive as possible and require that field workers attend a course before starting to map and offer supplementary training and supervision throughout the whole project. Nevertheless, our experience from several years of fieldwork shows the need to minimize amount of subjective assessments, in order to get reliable results. We therefore now use calculated validation based on the mapped object features but keep the field workers validation as well.

The mapping process requires certain training and practice. People often struggle to see the whole picture or fail to understand how the data are being processed within the database. Even a small section with a gradient of $18^{\circ}$ makes a track inaccessible even though the rest might be just fine as a gradient above a certain value is a criterion for exclusion. A picnic spot can be accessible but if it is placed in a middle of a field or on a sandy 
beach it still can't be reached. That information has to be mapped as well as in that case the access way is the exclusion criteria. But a walkway that meets the criteria for width for the most part, but has some narrow sections, with enough space for only one wheelchair, is still accessible as the requirements that two wheelchairs has to be able to pass each other does not necessarily apply to the whole length of the walkway. However, the walkway must be mapped with the wider value to make the automatic validation work.

\subsection{Results}

In order to analyze the results no special skills are required but an understanding of the mapping method is necessary

Tracks and walkways for instance, are mapped in sections either when divided by crossings or when object features change. That means that a section can be just a few or many meters long. Mapping this way makes it easier to spot inaccessible areas, but also requires attention to that detail in data analysis. To be able to interpret the results of data analyses, it is important to have a basic knowledge of the technical standards the classification scheme is based on, i.e. to know which object features are crucial for the assessment of the two target groups and what the critical values are.

When comparing municipalities it also has to be considered, that some towns are less accessible simply because of old building structure or their topography.

Mapping, keeping the data updated and data use therefore requires a certain continuity in staff responsible for the topic as well as financial support, something municipalities in Norway often do not have.

We are aware that the system is not perfect as it lies in the nature of standardization that complex data are simplified, but we still believe our data will be a valuable contribution to amongst others municipal and recreational planning and development of national statistics.

\section{References}

The Norwegian Government, Norway universally designed by 2025 - The Norwegian government's action plan for universal design and increased accessibility 2009-2013, Publication number: Q-1159 E, Norwegian Ministry of Children and Equality Oslo, $2009 . \quad$ Retrieved from: https://www.regjeringen.no/globalassets/upload/bld/ned satt-funksjonsevne/norway-universally-designed-by2025-web.pdf.

A.N. Laakso, M., Sarjakoski, T, Lehto, L.\& T.Sarjakoski, An Information Model for Pedestrian Routing and Navigation Databases Supporting Universal Accessibility, Cartographica 48:2 (2013), 89-99.

Standard Norge, Universal design of developed outdoor areas - Requirements and recommendations. Norsk Standard NS 11005:2011, Standard Norge Lysaker, 2011.

Direktorat for byggkvalitet, Byggteknisk forskrift (TEK10), Publikasjonsnummer: HO-2/2011, 2011.
Retrieved from: http://dibk.no/globalassets/byggtekniskforskrift-tek10/byggteknisk-forskrift-tek-10veiledningen-til-byggteknisk-forskrift---direktoratet-forbyggkvalitet_mai-2016.pdf.

Norsk Arbeids- og velferdsetaten (NAV), Elektriske rullestoler - et temahefte om formidling av elektriske rullestoler. Rikstrygdeverket, 2000. Retrieved from: https://www.nav.no/ o/Lokalt/Oslo/NAV

+ Hjelpemiddelsentral+Oslo+og+Akershus/Lokal+inform asjon/temahefter--384987. 